\title{
Bazı Aromatik Bitkilerin Geleneksel Lavaş Peyniri Üretiminde Biyosidal Etkileri
}

\author{
Serap KILIÇ ALTUN ${ }^{1}$, Hikmet DiNÇ², Hisamettin DURMAZ ${ }^{1 *}$ \\ ${ }^{1}$ Harran Üniversitesi, Veteriner Fakültesi, Gıda Hijyeni ve Teknolojisi Anabilim Dalı, Şanlıurfa, Türkiye. \\ ${ }^{2}$ Harran Üniversitesi, Veteriner Fakültesi, Farmakoloji ve Toksikoloji Anabilim Dalı, Şanlıurfa, Türkiye.
}

Özet: Bu araştırmanın amacı geleneksel lavaş peyniri üretiminde kullanılan bazı aromatik bitkilerin biyosidal etkilerini belirlemektir. Araştırma kapsamında geleneksel üretim tekniği ile inek sütünden çörekotlu (Nigella sativa), kekikli (Thymus vulgaris), biberli (Capsicum annuum), reyhanlı (Ocimum basilicum) ve sade olmak üzere deneysel olarak 5 farklı lavaş peyniri üretilmiştir. Üretilen peynirlerden 2. gün ve salamura aşamasını takiben 16. gün konvansiyonel kültür yöntemiyle toplam aerob mezofilik mikroorganizma, fekal koliform ve $E$. coli yönünden analizleri yapılmıştır. Mikrobiyolojik analiz sonuçlarına göre, üretimin 2. gününde ortalama toplam aerob mezofilik bakteri, fekal koliformlar ve $E$. coli sayıları sırasıyla; çörekotlu peynir örneklerinde 8.04, 4.98 ve $3.38 \log _{10} \mathrm{kob} / \mathrm{g}$; kekikli peynir örneklerinde 8.76, 4.62 ve $4.47 \log _{10} \mathrm{kob} / \mathrm{g}$; biberli peynir örneklerinde $8.41,4.60$ ve $4.77 \log _{10} \mathrm{kob} / \mathrm{g}$; reyhanlı peynir örneklerinde $8.71,4.11$ ve $4.04 \log _{10} \mathrm{kob} / \mathrm{g}$ ve sade peynir örneklerinde ise 8.82, 4.62 ve $4.92 \log _{10} \mathrm{kob} / \mathrm{g}$ iken, muhafazanın 16. gününde aynı mikroorganizmaların ortalama sayıları sırasıyla çörekotlu peynir örneklerinde 7.39, 3.07 ve $3.17 \log _{10} \mathrm{kob} / \mathrm{g}$; kekikli peynir örneklerinde $7.59,3.98$ ve $3.96 \log _{10}$ kob/g; biberli peynir örneklerinde 7.30, 2.00 ve $2.69 \log _{10} \mathrm{kob} / \mathrm{g}$; reyhanlı peynir örneklerinde 7.38, 2.69 ve $3.38 \log _{10} \mathrm{kob} / \mathrm{g}$ ve sade peynir örneklerinde 7.07, 2.47 ve $2.84 \log _{10} \mathrm{kob} / \mathrm{g}$ seviyelerinde olduğu tespit edilmiştir. Bu araştırmada, sade ve aromatik bitki ilave edilerek üretilen lavaş peyniri örnekleri arasında mikroorganizma yükü açısından herhangi bir farklılık belirlenememiştir. Sonuç olarak, araştırmada kullanılan aromatik bitkilerin geleneksel lavaş peynir örneklerinde bulunan mikroorganizmalar üzerine biyosidal etkisinin olmadığı kanaatine varılmıştır.

Anahtar Kelimeler: Aromatik bitki, Biyosidal etki, Lavaş peyniri.

\section{Biocidal Effects of Some Aromatic Plants on the Production of Traditional Lavas Cheese}

\begin{abstract}
The aim of this study was to determine the biocidal effects of some aromatic plants used in traditional lavas cheese production. Within the scope of the study, five different types of lavas cheese were experimentally produced from cow milk with traditional production technique, including black cumin (Nigella sativa), thyme (Thymus vulgaris), pepper (Capsicum annuum), purple basil (Ocimum basilicum) and plain. The produced cheeses were analyzed on the 2 nd day after production and on the 16th day after the brine stage in terms of total aerobic mesophilic bacteria, fecal coliform, and E. coli by conventional culture method. According to the results of microbiological analysis, on the 2 nd day of production, the total number of aerobic mesophilic bacteria microorganisms, fecal coliforms and $E$. coli counts were; $8.04,4.98$ and $3.38 \log _{10}$ $\mathrm{cfu} / \mathrm{g}$ in cheese samples with black cumin; 8.76, 4.62 and $4.47 \log _{10} \mathrm{cfu} / \mathrm{g}$ in cheese samples with thyme; $8.41,4.60$ and 4.77 $\log _{10} \mathrm{cfu} / \mathrm{g}$ in cheese samples with pepper; $8.71,4.11$ and $4.04 \log _{10} \mathrm{cfu} / \mathrm{g}$ in cheese samples with purple basil; 8.82, 4.62 and $4.92 \log _{10} \mathrm{cfu} / \mathrm{g}$ in plain cheese samples while on the 16 th day of storage $7.39,3.07$ and $3.17 \log _{10} \mathrm{cfu} / \mathrm{g}$ in cheese samples with black cumin; 7.59, 3.98 and $3.96 \log _{10} \mathrm{cfu} / \mathrm{g}$ in cheese samples with thyme; 7.30, 2.00 and $2.69 \log _{10} \mathrm{cfu} / \mathrm{g}$ in cheese samples with pepper; 7.38, 2.69 and $3.38 \log _{10} \mathrm{cfu} / \mathrm{g}$ in cheese samples with purple basil; 7.07, 2.47 and $2.84 \log _{10}$ $\mathrm{cfu} / \mathrm{g}$ in plain cheese samples, respectively. In this study, no difference was found in the microorganism load between lavas cheese samples produced with orwithout aromatic plant additions. As a result, it was concluded that aromatic plants used in this study did not have any biocidal effect on microorganisms found in traditional lavas cheese samples.

Keywords: Aromatic plant, Biocidal effect, Lavas cheese.
\end{abstract}

\section{Giriş}

Ülkemizde fermente süt ürünleri oldukça zengin bir çeşitliliğe sahiptir ve bileşimlerindeki organik (protein, yağ, karbonhidrat, vitamin) ve inorganik (mineraller) bileşenlerden dolayı beslenmedeki fonksiyonları önemlidir (Ayar ve Akyüz., 2003). Türkiye'de yaygın olarak üretilen beyaz, kaşar ve tulum peynirlerinin yanısıra (Altun ve Köse, 2014), yöresel olarak geleneksel yöntemlerle üretilen ve isimlendirilen birçok peynir çeşidi bulunmaktadır (Kamber, 2015). Türkiye İstatistik Kurumu verilerine göre ülkemizde 2017 yılında 638.406 ton ile inek peyniri diğer peynir türlerine göre en çok üretilen peynir çeşidi olup, üretilen bu peynirlerin büyük bir kısmını beyaz peynir ve \%10'unu ise lavaş peyniri gibi yöresel peynirler oluşturmaktadır (Anonim, 2017; 
Hayaloğlu, 2008). Lavaş peyniri özellikle Antakya ili ve çevresinde üretilen, yörede sıkma peynir, ezme peynir gibi farklı isimlerle adlandırılan ve telemesi haşlanarak elde edilen bir peynir çeşididir. Lavaş peyniri üretiminde genellikle inek sütü kullanılmaktadır (Tarakçı ve ark., 2004).

Ülkemizde aromatik bitkilerin geleneksel üretim tekniği ile üretilen peynirlere lezzet ve aroma vermek amacıyla kullanıldığı bilinmektedir. Gıda üretiminde kullanılan kimyasal koruyucuların insan sağlığına olumsuz etkilerinden dolayı kullanımı giderek azalmakta ve yerini aromatik bitkiler gibi doğal koruyucular almaktadır. Benzer şekilde lavaş peynirinde de ticari olarak çörek otu (Nigella sativa), kekik (Thymus vulgaris) ve biber (Capsicum annuum) gibi aromatik bitkiler kullanılmaktadır. Aromatik bitkilerin gıda üretiminde kullanımının aromatik özelliklerinin yanısıra antioksidatif ve biyosidal etkileriyle hijyenik kalite ve raf ömrüne olumlu etkileri bulunmaktadır (Beuchat ve Golden, 1989). Ülkemiz, farklı iklim özellikleriyle 3000'i endemik olan yaklaşık 9000 bitki türüne sahip bir coğrafyadadır ve 500 civarında bitki türü, değerli tıbbi aromatik ve boya amaçlı kullanılmaktadır (Paksoy, 2016). Bu aromatik bitkilerden çörek otu ile yapılan bir araştırmada çörek otunun E.coli'ye karşı konsantrasyona bağımlı inhibisyon etkisi olduğu belirlenmiştir (El-Fatatry, 1975). Kalsiyum, magnezyum ve demir gibi mineraller ile $C$ ve $K$ vitamini yönünden iyi bir kaynak olan kekiğin biyosidal etkisinin yanı sıra antioksidan ve hücre koruyucu özelliğinin de olduğu bildirilmektedir (Paksoy, 2016). Kekiğin S. Typhimurium, S. aureus ve $V$. parahaemolyticus üzerine biyosidal etkilerinin araştırıldığı bir araştırmada, S. aureus'un gelişimini \%0.05 konsantrasyonda inhibe ettiği belirlenmiştir (Aktuğ ve Karapınar, 1988). Biber, bileşiminde bulunan karotenoit bileşenlerinden $\beta$-karoten, kriptoksantin ve kapsantin ile gıdalarda renk verici olarak ve antioksidan özelliğinden dolayı yaygın olarak kullanılmaktadır. Tavacı (1997)'nın yapmış olduğu bir araştırmada, \%5 pulbiber ilavesi ile hazırlanan kaşar peynirinde maya-küf sayısının kontrol grubundan daha düşük olduğu rapor edilmiştir. Reyhan, manganez, potasyum, kalsiyum ve A vitamini bakımından değerli bir aromatik bitkidir (Paksoy, 2016). Amrita ve ark. (2009)'larının yapmış olduğu bir araştırmada fesleğen ve çeşitli aromatik bitkilerin $E$. coli'ye karşı biyosidal etkilerinin olduğu belirlenmiştir. Bu araştırmanın amacı, geleneksel lavaş peynir üretiminde kullanılan bazı aromatik bitkilerin (çörek otu, kekik, pul biber, reyhan) biyosidal etkilerinin belirlenmesi amaçlanmıştır.

\section{Materyal ve Metot}

Materyal: $\mathrm{Bu}$ araştırmada Harran Üniversitesi Veteriner Fakültesi Gıda Hijyeni ve Teknolojisi Laboratuvar'ında farklı aromatik bitkiler kullanılarak ve sade olarak üretilen lavaş peynir örnekleri materyal olarak kullanılmıştır. Ağırlıkça \%2 oranında hassas terazide tartılarak hazırlanan kurutulmuş çörek otu, kekik, pul biber ve reyhan bitkileri koagülasyon sırasında peynir pıhtısı şekillenmeden lavaş peynirlere ilave edilmiş ve toplamda her biri 200'er gramlık 5 farklı lavaş peynir örneği üretilmiştir.

Lavaş Peyniri Örneklerinin Hazırlanması: Lavaş peyniri üretiminde kullanılan çiğ inek sütü Harran Üniversitesi Ziraat Fakültesi çiftliği'nden temin edildi. Ön testleri yapılan inek sütü $73^{\circ} \mathrm{C}^{\prime}$ de 15 saniye pastörize edildi. Kontrol grubu olarak üretilen sade peynir dışındaki gruplara \%2 oranında aromatik bitkiler ilave edildikten sonra kuvveti $1 / 60.000$ olan maya $1: 10$ oranında sulandırılarak katıldı ve pıhtılaşma sağlanıncaya kadar 2 saat beklendi. İnkubasyonun ardından şekillenen pıhtı baskılandı ve sonrasında dilimlenerek \%4 oranında tuzlandı ve bu aşamada rutubetinin azalması sağlandı. Elde edilen teleme, haşlama işleminin ardından şekillendirilerek \%12 salamurada olgunlaşmaya bırakıldı (Tarakçı ve ark., 2004). Üretilen peynirlerden 2. gün ve salamura aşamasını takiben 16. gün konvansiyonel kültür yöntemiyle toplam aerob mezofilik bakteri, fekal koliformlar ve E.coli yönünden analizleri yapıldı.

Toplam Aerob Mezofilik Bakteri Sayımı: Her bir grupta bulunan dilüsyonu hazırlanmış örneklerden 1'er mL alınarak Plate Count Agar (Merck 105463)'a yayma plak yöntemi ile ekimler yapılarak $37^{\circ} \mathrm{C}^{\prime}$ de 48 saat inkübasyona bırakıldı ve petrilerde oluşan tüm koloniler sayılıp seyreltme faktörü ile çarpılarak mikroorganizma sayıları hesaplandı.

Fekal Koliform Sayımı: Lauryl Sülfat Broth (Merck $110266)^{\prime}$ ta $37^{\circ} \mathrm{C}^{\prime}$ de 24 saat inkübasyon sonrası pozitif sonuç veren tüplerden EC Broth (Merck $110765)^{\prime}$ a ekim yapıldı ve $44.5^{\circ} \mathrm{C}^{\prime}$ de $24-48$ saat inkübasyon sonunda pozitif sonuç veren örnekler fekal koliform grubu bakteriler olarak değerlendirildi (Doğan ve ark., 2001).

E.coli sayımı: 10 g peynir örneği $90 \mathrm{~mL}$ MRD (Merck 112535) ile homojenize edildi. Homojenizasyonun ardından Chromocult TBX Agar (Merck 116122)'a ekim yapıldı ve petriler $44^{\circ} \mathrm{C}^{\prime}$ de $18-24$ saat inkübe edildi. Chromocult TBX Agar'da üreyen mavi-yeşil 
renkteki tipik koloniler sayılarak seyreltme faktörü ile hesaplandı (Doğan ve ark., 2001).

\section{Bulgular}

Mikrobiyolojik analiz sonuçlarına göre, üretimin 2. gününde ortalama toplam aerob mezofilik bakteri sayısı (TAMB), fekal koliformlar ve E. coli sayıları sırasıyla; çörekotlu peynir örneklerinde $8.04,4.98$ ve $3.38 \log _{10} \mathrm{kob} / \mathrm{g}$, kekikli peynir örneklerinde $8.76,4.62$ ve $4.47 \log _{10} \mathrm{kob} / \mathrm{g}$, pul biberli peynir örneklerinde $8.41,4.60$ ve 4.77 $\log _{10} \mathrm{kob} / \mathrm{g}$, reyhanlı peynir örneklerinde 8.71, 4.11 ve $4.04 \log _{10} \mathrm{kob} / \mathrm{g}$ ve sade peynir örneklerinde ise $8.82,4.62$ ve $4.92 \log _{10} \mathrm{kob} / \mathrm{g}$ olarak belirlenmiştir (Tablo 1). Muhafazanın 16. gününde aynı mikroorganizmaların sayılarının sırasıyla çörekotlu peynir örneklerinde $7.39,3.07$ ve $3.17 \log _{10} \mathrm{kob} / \mathrm{g}$, kekikli peynir örneklerinde $7.59,3.98$ ve $3.96 \log _{10}$ kob/g, pul biberli peynir örneklerinde 7.30, 2.00 ve $2.69 \log _{10} \mathrm{kob} / \mathrm{g}$, reyhanlı peynir örneklerinde 7.38, 2.69 ve $3.38 \log _{10} \mathrm{kob} / \mathrm{g}$ ve sade peynir örneklerinde $7.07,2.47$ ve $2.84 \log _{10} \mathrm{kob} / \mathrm{g}$ seviyelerinde oldukları tespit edilmiştir (Tablo 2).

Tablo 1. Üretimin 2. gününde lavaş peynir örneklerinin mikrobiyolojik analiz sonuçları $\left(\log _{10}\right.$ kob/g).

\begin{tabular}{lccc}
\hline & $\begin{array}{c}\text { TAMB } \\
\text { sayısı }\end{array}$ & $\begin{array}{c}\text { Koliform } \\
\text { sayısı }\end{array}$ & $\begin{array}{c}\text { E.coli } \\
\text { sayısı }\end{array}$ \\
\hline Çörekotlu & 8.04 & 4.98 & 3.38 \\
Kekikli & 8.76 & 4.62 & 4.47 \\
Pul biberli & 8.41 & 4.60 & 4.77 \\
Reyhanlı & 8.71 & 4.11 & 4.04 \\
Kontrol Sade & 8.82 & 4.62 & 4.92 \\
\hline
\end{tabular}

Tablo 2. Muhafazanın 16. gününde lavaş peynir örneklerinin mikrobiyolojik analiz sonuçları $\left(\log _{10}\right.$ kob/g).

\begin{tabular}{lccc}
\hline & $\begin{array}{c}\text { TAMB } \\
\text { sayısı }\end{array}$ & $\begin{array}{c}\text { Koliform } \\
\text { sayısı }\end{array}$ & $\begin{array}{c}\text { E.coli } \\
\text { sayısı }\end{array}$ \\
\hline Çörekotlu & 7.39 & 3.07 & 3.17 \\
Kekikli & 7.59 & 3.98 & 3.96 \\
Pul biberli & 7.30 & 2.00 & 2.69 \\
Reyhanlı & 7.38 & 2.69 & 3.38 \\
Kontrol Sade & 7.07 & 2.47 & 2.84 \\
\hline
\end{tabular}

\section{Tartışma ve Sonuç}

Aromatik bitkilerin biyosidal etkileri; organik asitler, aldehitler, fenolikler, flavonoidler, terpenoidler, kinonlar, tanenler, alkaloidler ve saponinler gibi bileşikler ile oksijen ikameli metabolitlerinden kaynaklıdır. Aromatik bitkilerde bulunan bu bileşiklerin kimyasal farklılıkları biyosidal etkilerini değiştirmektedir (Göncü ve Akın, 2017). Bu bileşiklerde bulunan hidroksil gurupları, mikroorganizma hücre duvarınının yapısını bozarak biyosidal etki göstermektedir (Gyawali ve İbrahim, 2014). Peynir üretiminde aromatik bitkiler; biyosidal etkileri, kitlesel kusurları önlemesi, aroma, renk ve tat vermesi ile ürünün raf ömrünü uzatması gibi nedenlerle yaygın olarak kullanılmaktadır (Shan ve ark., 2007). Ülkemizde peynir üretiminde yaygın kullanılan bazı aromatik bitkiler; kekik, fesleğen, çörek otu, pul biber, karabiber, reyhan ve bayır turbu olarak sayılabilir. Dağdelen (2010)'in yapmış olduğu bir araştırmada, peynirde kullanılan aromatik bitkilerin peynir üretiminde laktik asit bakterilerine biyosidal etkisinin olmadığı bildirilmiştir. Ayar ve Akyüz (2003) olgunlaşma süresince beyaz peynirin lipolizi üzerine yapmış oldukları bir araştırmada ise kekik ve nane ekstraktlarının maya-küf oluşumunu bir miktar önlendiğini rapor etmişlerdir. Diğer taraftan Smith ve ark. (2001)'nın yapmış olduğu başka bir araştırmada; sarımsak, defne, kekik ve tarçın özütü ilavesi ile hazırlanan yumuşak peynirlerin $L$. monocytogenes ve $S$. Enteriditis suşları ile kontamine edildiğinde tam yağlı yumuşak peynirlerde kekik yağının S. Enteritidis'e karşı etkisiz olduğunu rapor etmişlerdir. Masatcıoğlu (2004)'nun gerçekleştirdiği bir araştırmada tarçın, biber, yeni bahar, kekik, kimyon, karanfil, karabiber, nane, hindistan cevizi, salça ve tuz ilave edilerek üretilen farklı kombinasyonlardaki sürk peynirlerinin $S$. aureus ile kontamine edildiğinde kullanılan aromatik bitkilerin biyosidal etkilerinin olmadığını ve $S$. aureus sayısının olgunlaşma periyodu ile azaldığını rapor etmiştir. Araştırmacının bulguları, yapılan bu araştırmada elde edilen bulgularla benzerlik göstermektedir. Hassanien ve ark. (2013)'nın çörek otu ilavesi ile hazırlanan domiati peynirleriyle yapmış oldukları araştırmada toplam aerob mezofilik mikroorganizma sayısında belirgin bir değişimin olmadığını, E. coli ve $S$. aureus sayılarında ise azalma olduğunu rapor etmişlerdir. Akarca (2013)'nın yapmış olduğu araştırmada ise mozarella peynir üretiminde farklı kombinasyonlarda ilave edilen aromatik bitkilerin koliform grubu mikroorganizmalara ve Stafilokoklara etkisinin olduğu, fakat proteolitik mikroorganizma sayısında ise artış gözlendiği rapor edilmiştir. Paksoy (2016) tarafından yapılan bir araştırma ultrafiltre beyaz peynirlere ağırlıkça \%0.5 oranında fesleğen, dereotu, kekik, sarımsak tozu, çörek otu ve frenk soğanı ilave edilmiş, toplam aerob mezofilik mikroorganizmalar üzerine en etkin aromatik bitkinin çörek otu olduğu, kekik ve sarımsak 
tozunun da maya-küf üzerine etkili olduğu bildirilmiştir.

Sonuç olarak bu araştırmada, sade ve aromatik bitki ilave edilerek üretilen lavaş peyniri örnekleri arasında mikroorganizma yükü açısından herhangi bir farklılık belirlenememiş olup kullanılan aromatik bitkilerin lavaş peyniri örneklerindeki mikroorganizmalar üzerine biyosidal etkisinin olmadığı kanaatine varılmıştır. Örneklemlerin yanlızca üretimin 2. ve 16. günlerde yapılması ve lavaş peynirinin telemesi haşlanarak yapılan bir peynir olması, araştırmada kullanılan aromatik bitkilerin biyosidal etki göstermemelerine sebep olabilir. Bu sebeple farklı peynir çeşitlerinde aromatik bitkilerin özellikle patojen mikroorganizmalar üzerine biyosidal ve antioksidan etkileri araştırılmalıdır.

\section{Bilgilendirme}

Bu araştırma 25-29 Mart 2018 tarihinde Antalya'da düzenlenen IV. Uluslararası Biyosidal Kongresi'nde sözlü bildiri olarak sunulmuştur.

\section{Kaynaklar}

Akarca G, 2013: Kılıflanmış sade ve baharatlı mozzarella peynirinin olgunlaşma süresinde değişimlerin incelenmesi. Doktora Tezi, Afyon Kocatepe Üniversitesi Fen Bilimleri Enstitüsü, Afyonkarahisar.

Aktuğ ŞE, Karapınar M, 1988: Sensitivity of some common food poisoning bacteria to thyme, mint and bay leaves. Int J Food Microbiol, 3, 349-354.

Altun I, Köse Ş, 2014: Kahramanmaraş-Elbistan bölgesinde üretilen Kelle peynirinin kimyasal ve biyokimyasal özellikleri. In: 4. Geleneksel Gıdalar Sempozyumu, Adana, s. 270.

Amrita V, Sonal D, Shalini, R, 2009: Antibacterial effect of herbs and spices extract on Escherichia coli. Electronic Journal of Biology, 5, 40-44.

Anonim,2017:http://www.tuik.gov.tr/PreHaberBultenleri. do;jsessionid=7Hr2hxgK8cVVZ9gLLjnMSsGG9WTgL4 HpQ1PhxpHMwQ2yp2lyTTfG!650214861?id=24687, Erişim tarihi; 07.05.2018.

Ayar A, Akyüz N, 2003: Olgunlaşma esnasında beyaz peynirin lipolizi üzerine ilave edilen bazı baharat ekstraklarının etkisi. Gıda, 28, 295-303.

Beuchat LR, Golden DA, 1989: Antimicrobials occurring naturally in foods. Food Technol, 43, 134-142.

Dağdelen Ş, 2010: Otlu peynire katılan önemli ot türlerinin antimikrobiyal, antioksidan etkileri, aroma profili ve bazı kimyasal özelliklerinin belirlenmesi. Yüksek Lisans Tezi, İnönü Üniversitesi Fen Bilimleri Enstitüsü, Malatya.

Doğan HB, Çakır I, Keven F, Coşansu S, Kıral N, Dağer Ti, Gürsu G, Halkman AK, 2001: Çeşitli gıdalarda koliform, fekal koliform ve E. coli varlığı. Gıda, 26, 83-90.
El-Fatatry HM, 1975: Isolation and structure assignment of an antimicrobial principle from the volatile oil of Nigella sativa L. seeds. Pharmazie, 30, 109-111.

Göncü B, Akın MS, 2017: Baharat çeşitlerinin peynirde kullanımı. Harran Üniversitesi Mühendislik Dergisi, 2, 44-53.

Gyawali R, Ibrahim SA, 2014: Natural products as antimicrobial agents. Food Control, 46, 412-429.

Hassanien MFR, Mahgoub SA, El-Zahar KM, 2014: Soft cheese supplemented with black cumin oil: Impact on food borne pathogens and quality during storage. Saudi Journal of Biological Sciences, 21, 280-288.

Hayaloğlu AA, 2008: Türkiye'nin peynirleri-genel bir perspektif. In: Türkiye 10. Gıda Kongresi, Erzurum, s. 729-732.

Kamber U, 2015: Traditional Turkey cheeses and their classification. Van Veterinary Journal, 26, 161-171.

Masatcıoğlu MT, 2004: Sürk peyniri üretiminde kullanılan çeşni maddelerinin depolama koşullarının ve süresinin Staphylococcus aureus'un canlılığı üzerine etkisi. Yüksek Lisans Tezi, Mustafa Kemal Üniversitesi Fen Bilimleri Enstitüsü, Hatay.

Paksoy G, 2016: Bazı baharatların ultrafiltre beyaz peynir kalitesi üzerine etkileri Yüksek Lisans Tezi, Namık Kemal Üniversitesi Fen Bilimler Enstitüsü, Tekirdağ.

Shan B, Cai YZ, Brooks JD, Corke H, 2007: The in vitro antibacterial activity of dietary spice and medicinal herb extracts. Int J Food Microbiol, 117, 112-119.

Smith-Palmer A, Stewart J, Fyfe L, 2001: The potential application of plant essential oils as natural food preservatives in soft cheese. Food Microbiology, 18, 463-470.

Tarakçı Z, Durmaz H, Sağun E, Aygün O, 2004: Hatay sıkma peynirinin kimyasal özellikleri ile proteoliz ve lipoliz düzeylerinin araştırılması. Vet Bil Derg, 20, 53-59.

Tavacı MÇ, 1997: Çeşitli baharatların ilavesi ile yapılan vakum paketlenmiş kaşar peynirleri üzerine bir araştırma. Yüksek Lisans Tezi, Namık Kemal Üniversitesi Fen Bilimleri Enstitüsü, Tekirdağ.

*Yazışma Adresi: Hisamettin DURMAZ,

Harran Üniversitesi, Veteriner Fakültesi, Besin Hijyeni ve Teknolojisi Anabilim Dalı, Eyyübiye Kampüsü/Şanlıurfa. e-mail: hisamettindurmaz@yahoo.com 